\title{
COMUNICAÇÃo
}

\section{AVALIAÇÃO DA EVENTUAL ATIVIDADE TERAPÊUTICA DA PLANTA RUBIM NA INFECÇÃO EXPERIMENTAL DE CAMUNDONGOS PELO PLASMODIUM BERGHEI}

\author{
Vicente Amato Neto, Lucia Maria Almeida Braz, \\ Gokithi Akisue e Maria Helena Colameo Motta.
}

Diversas possibilidades terapêuticas concretas têm nexo com a utilização de plantas, das quais por vezes são inclusive identificados e sintetizados os princípios ativos. Exemplo recente no âmbito das doenças parasitárias é hoje a viabilidade de emprego da artemisinina, eficiente no sentido de beneficiar pacientes com malária, advindo esse medicamento de conhecimentos popularmente acumulados na China ${ }^{3}$.

Observações de leigos, por vezes tradicionalmente coletadas, podem merecer atenção e a valorização de algumas delas propiciou a consolidação de remédios amplamente usados. Por considerar válidas ocorrências de tais naturezas decidimos empreender estudo referente ao rubim, cujo sumo, conforme fatos a nós relatados, possuiria a capacidade de debelar infecção palúdica humana.

Para realizar a necessária investigação, recorremos a modelo experimental baseado em parasitismo de camundongos pelo Plasmodium berghei $i^{4}$.

Leonurus sibiricus $\mathrm{L}$. é rotineiramente mencionado como rubim ou cordão de frade e faz parte da família Labiatae, composta por 200 gêneros e cerca de 3200 espécies, extensamente distribuídas no mundo ${ }^{2}$.

Utilizamos 50 camundongos Balb-C, cada um com $20 \mathrm{~g}$ de peso, separados em cinco grupos de $\operatorname{dez}\left(A 1, A 2, B 1, B 2\right.$ e C). Infectamos $30 \operatorname{com} 10^{6}$ formas do hematozoário, contidas em $0,1 \mathrm{ml}$ de

\footnotetext{
Laboratório de Investigaçâo Médica-Parasitologia do Hospital das Clínicas, Faculdade de Medicina da Universidade de São Paulo. Laboratório de Farmacognosia, da Faculdade de Ciências Farmacêuticas da Universidade de São Paulo.

Endereço para correspondência: Prof. Vicente Amato Neto. Laboratório de Investigação Médica-Parasitologi.a Av. Dr. Amaldo 455, 01246 São Paulo, SP, Brasil.

Recebido para publicação em 12/09/91.
}

solução fisiológica e, para a contagem, correlacionamos a porcentagem de hemácias parasitadas, em esfregaço de sangue corado, com o número total de glóbulos, em câmara de Neubauer.

Em liquidificador obtivemos duas preparações de rubim, ou seja, em $200 \mathrm{ml}$ de água destilada colocamos $100 \mathrm{~g}$ de caules ou de folhas e partes aéreas pouco antes colhidos. Geladeira serviu para conservação e a administração começou, cotidianamente, quatro dias após o aviamento, por meio de sonda gástrica e volume de $0,5 \mathrm{ml}$, estando os roedores em jejum. $O$ tratamento principiou na data de inoculação do plasmódio e perdurou até o final da experimentação.

Quanto aos grupos, especificamos a seguir o que correspondeu a eles: A1 - infectados, receberam preparação de caules; A2 - não infectados, receberam preparação de caules; B1 - infectados, receberam preparação de folhas e partes aéreas; B2 - não infectados, receberam preparação de folhas e partes aéreas; C - infectados, não receberam preparações.

Avaliamos as parasitemias em dias alternados, comprovamos números crescentes de plasmódios desde 72 horas após as inoculações e notamos os comportamentos adiante consignados a propósito das mortes de todos os componentes: A1 - entre o quinto e o vigésimo-quarto dias; B1 - entre o sexto e o vigésimo-sexto dias; $C$ - entre o oitavo e o décimo-sexto dias. Nos contingentes A2 e B2 os camundongos permaneceram vivos.

Pelo menos de acordo como procedemos, o rubim não revelou efetividade, contrariando os pareceres dos que julgaram ter conseguido proveitos através dele. $O P$. berghei presta-se, sem dúvida, a triagens de caráter terapêuticoe, no presente estudo, permitiu conclusão válida, atinente de um lado à intenção de não desprezar simplesmente concepções populares e, de outro, a deduzir pela inatividade quando adotada tática para decisão. 
Comunicação. Amato Neto V, Braz LMA, Akisue G, Motta MHC. Avaliação da eventual atividade terapêutica da planta Rubim na infecção experimental de camundongos pelo Plasmodium berghei. Revista da Sociedade Brasileira de Medicina Tropical 24:263-264, out-dez, 1991

\section{REFERÊNCIAS BIBLIOGRÁFICAS}

1. Allison AC, Eugui EM. A radical interpretation of immunity to malaria parasites. The Lancet II:1431$1433,1982$.

2. Hoehne FC. Plantas e substâncias vegetais tóxicas e medicinais. Graphicans, São Paulo e Rio de Janeiro p.250-251, 1939.

3. Klayman DL. Qinghaosu (artemisinin): an antimalarial drug from China. Science 228:10491054, 1985.

4. Peters W, Portus JM, Robinson BL. The chemotherapy of rodent malaria, XXII. The value of drug resistant strains of $P$. berghei in screening forblood schizontocidal activity. Annals of Tropical Medicine and Parasitology 69:155-171, 1975. 